Published in final edited form as:

Int J Obes (Lond). 2015 January ; 39(1): 114-120. doi:10.1038/ijo.2014.79.

\title{
Association between MC4R rs17782313 Polymorphism and Overeating Behaviours
}

\author{
Zeynep Yilmaz, $\mathrm{PhD}^{1,2}$, Caroline Davis, $\mathrm{PhD}^{2,3,4}$, Natalie J. Loxton, $\mathrm{PhD}^{5}$, Allan S. Kaplan, \\ MD, FRCP(C) $)^{2,6,7}$, Robert D. Levitan, MD, $\operatorname{FRCP}(C)^{6,7,8}$, Jacqueline C. Carter, $\mathrm{PhD}^{9}$, and \\ James L. Kennedy, MD, FRCP(C) $6,7,10$ \\ ${ }^{1}$ Center of Excellence for Eating Disorders, University of North Carolina at Chapel Hill, Chapel \\ Hill, NC \\ ${ }^{2}$ Clinical Research Department, Centre for Addiction and Mental Health, Toronto, Ontario, \\ Canada \\ ${ }^{3}$ Kinesiology \& Health Sciences, York University, Toronto, Ontario, Canada \\ ${ }^{4}$ Eating Disorders Program, Toronto General Hospital, Toronto, Ontario, Canada \\ ${ }^{5}$ School of Psychology, The University of Queensland, Brisbane, Queensland, Australia \\ ${ }^{6}$ Institute of Medical Science, University of Toronto, Toronto, Ontario, Canada \\ ${ }^{7}$ Department of Psychiatry, University of Toronto, Toronto, Ontario, Canada \\ ${ }^{8}$ Mood and Anxiety Program, Centre for Addiction and Mental Health, Toronto, Ontario, Canada \\ ${ }^{9}$ Department of Psychology, Memorial University, St. John's, Newfoundland, Canada \\ ${ }^{10}$ Neurogenetics Section, Centre for Addiction and Mental Health, Toronto, Ontario, Canada
}

\section{Abstract}

Background/Objectives-Melanocortins play a crucial role in appetite and weight regulation. Although the melanocortin 4 receptor $(M C 4 R)$ gene has been repeatedly linked to obesity and antipsychotic-induced weight gain, the mechanism behind how it leads to this effect in still undetermined. The goal of this study was to conduct an in-depth and sophisticated analysis of $M C 4 R$ polymorphisms, body mass index (BMI), eating behaviour, and depressed mood.

Subjects/Methods-We genotyped 328 individuals of European ancestry on the following $M C 4 R$ markers based on the relevant literature on obesity and antipsychotic-induced weight gain: rs571312, rs17782313, rs489693, rs11872992, and rs8087522. Height and weight were measured, and information on depressed mood and overeating behaviours was obtained during the in-person assessment.

Corresponding author: Caroline Davis, PhD, York University, 343 Bethune College, 4700 Keele Street, Toronto, Ontario, M3J 1P3, Canada, cdavis@yorku.ca.

${ }^{3}$ There was little change to results when controlling for gender ([total indirect effect $\left.=1.55,95 \mathrm{CI}=0.38 ; 2.95\right][\mathrm{BDI}$ indirect effect $=$. $2595 \mathrm{CI}=-0.31 ; 1.10]$ [eating indirect effect $=1.30 ; 95 \mathrm{CI}=0.27 ; 2.75]$ ).

Conflict of Interest

Dr. Kennedy has received honoraria from Eli Lilly and Roche, whereas Dr. Levitan has received honorarium from Astra-Zeneca.

Other authors have no financial interests to disclose. 
Results-BMI was associated with rs $17782313 \mathrm{C}$ allele; however this finding did not survive correction for multiple testing $(p=0.018)$. Although $r s 17782313$ was significantly associated with depressed mood and overeating behaviours, tests of indirect effects indicated that emotional eating and food cravings, rather than depressed mood, uniquely accounted for the effect of this marker and BMI $(n=152)$.

Conclusions-To our knowledge, this is the first study to investigate the link between MC4R rs17782313, mood and overeating behaviour, as well as to demonstrate possible mechanisms behind MC4R's influence on body weight. If replicated in a larger sample, these results may have important clinical implications, including potential for the use of MC4R agonists in the treatment of obesity and disordered eating.

\section{Keywords}

MC4R; candidate gene; weight gain; eating behaviour; emotional eating; food cravings; depression; obesity

\section{INTRODUCTION}

It is estimated that one billion adults worldwide are overweight or obese (1). The causes of obesity are complex, with biological, psychological, and environmental factors contributing to its etiology. Various hormones and neurotransmitter systems have been studied in relation to appetite and weight regulation in the hope of shedding light on the biological risk factors for overeating and obesity (2-4).

Melanocortins are expressed in the hypothalamus and play an important role in regulating appetite. Stimulation of brain melanocortin results in a decrease in food intake and weight; similarly, mutations and defects of the melanocortin 4 receptor $(M C 4 R)$ gene have been implicated in animal models and human studies of weight gain (5-7). Genome-wide association studies (GWAS) and meta-analyses of GWAS suggest that several markers near MC4R (e.g., rs17782313, rs571312) are strongly associated with obesity in healthy adults, adolescents, and children (8-13). There have also been small- and large-scale candidate gene studies that replicated the GWAS findings on $M C 4 R$ in various ancestral populations and age groups (14-16). More recently, a GWAS on second-generation antipsychoticinduced weight gain found a peak at $M C 4 R$ on chromosome 18, and an association with rs489693 (17). Similarly, rs8087522, identified as a putative transcription factor-binding site in the promoter region of the $M C 4 R$ gene, has been implicated in weight gain following the prescription of antipsychotic medications (18).

Although it is well documented that common variants near $M C 4 R$ are associated with an increased susceptibility for gaining weight, the mechanisms behind this effect are not fully understood. Animal studies have demonstrated that MC4R deficiency may be responsible for various metabolic and eating-related changes such as increased feeding (19) and high-fat hyperphagia (7). It is not clear, however, whether these models apply to the near $M C 4 R$ region, which is often not covered in animal knockout models. $M C 4 R$ rs17782313, located downstream of the $M C 4 R$ gene, has been studied extensively and replicated consistently in its relation to weight gain (8-16). Thus far, rs17782313 has not been linked to micro- or 
macro-nutrient intake $(20,21)$. In two preliminary studies of obese Chilean children, however, rs17782313 C homozygosity was associated with increased food-enjoyment scores and sweet snack consumption $(22,23)$. In summary, despite the well-established link between $M C 4 R$ common variants and body weight, no clear mechanism of action has been found to explain how these variants are associated with weight gain in the general population.

MC4R is also known to interact with the serotonin and dopamine pathways, thereby suggesting a possible involvement of MC4R in mood regulation. The relationship between melanocortins and serotonin has been well documented (24), and the effects of the antidepressant d-fenfluramine (a serotonin receptor $2 \mathrm{C}$ agonist) are significantly diminished in $M c 4 r$ knockout mice (25). At the molecular level, it has been recently demonstrated that MC4R signaling may be involved in triggering stress-induced synaptic adaptations in the nucleus accumbens, an area of the brain associated with reward processing and where dopamine is highly expressed (26). Furthermore, blocking MC4R signaling in this region has reversed anhedonia in rodents (26), demonstrating the possible link between dysphoria and melanocortins. Despite the evidence for a possible role of the melanocortin system in mood regulation, to date, no study has investigated whether there are links between $M C 4 R$ genetic variants and depressed mood nor explored how depressed mood, may affect eating behaviour or BMI in the presence of $M C 4 R$ genetic risk variants. One possibility is that MC4R predisposes individuals to weight gain via two related pathways: 1) via overeating behaviours and 2) via depressed mood.

The objectives of the current study were: 1 ) to examine the relationship between $M C 4 R$ markers and BMI; and 2) to investigate associations between $M C 4 R$ common variants and eating behaviours associated with over-consumption (viz. emotional eating, binge eating, food cravings, and hedonically-driven eating); and 3) to assess overeating behaviours and depressed mood as potential mediators of the predicted association between $M C 4 R$ and body mass index (BMI).

\section{METHODS}

\section{Participants}

Adults between the ages of 24 and 50 years ( 230 women and 98 men) were recruited through advertisements placed at universities, hospitals, other public institutions, and local newspapers in the Greater Toronto Area, as well as online sites such as Craigslist. All participants were of European ancestry. Exclusion criteria included: 1) not being fluent in English or having lived in North America for less than five years; 2) being post-menopausal or having a pregnancy within the previous six months for female participants; 3 ) a current or lifetime DSM-IV-TR diagnosis of any psychotic disorder, alcohol/substance abuse or dependence; or 4) diagnosis of a serious medical/physical illness such as cancer, heart disease, or paralysis. Current or past diagnosis or treatment of other psychiatric disorders did not lead to exclusion from study participation. Prior to the in-person assessment, all participants were screened over the phone by the research coordinator to confirm basic eligibility criteria. 
All aspects of this research study were reviewed and approved by the Centre for Addiction and Mental Health Research Ethics Board and conducted in accordance with the Helsinki Declaration as revised in 1989.

\section{Clinical measures}

BMI (weight in kilograms/height in metres ${ }^{2}$ ) was calculated from measured height and weight obtained during the in-person screen.

Depressed Mood was assessed using the Beck Depression Inventory (BDI) (27). BDI, which consists of 21 items covering the one-week time period before the assessment, is one of the most commonly used scales for the evaluation of mood in clinical and research settings. It captures a variety of depressive symptoms such as dysphoria, changes in eating patterns, sleep disturbances, and anhedonia. Cronbach's a coefficient in the present study was 0.94 .

Binge Eating was assessed by the five-item subscale of the Binge Eating Questionnaire (BEQ) (28), which includes frequency and severity of symptoms such as loss of control over eating, and negative affect following a binge. Cronbach's a coefficient was 0.85 .

Hedonically-Driven Eating was assessed by the Power of Food Scale (PFS) (29), a 21-item self-report questionnaire that assesses individual differences in the appetitive responsiveness to food independent of actual consumption (thus differentiating the motivation and appetitive drive for palatable foods from the tendency to overeat). Cronbach's a coefficient was 0.97 .

Emotional Eating was assessed by two separate questionnaires: i) the same-named subscale of the Dutch Eating Behaviour Questionnaire (DEBQ) (30), which reflects the degree to which eating behaviour is triggered by emotional states such as worry rather than by hunger (e.g., "Do you have the desire to eat when somebody lets you down?"); and ii) the Eating Behaviour Patterns Questionnaire (EBPQ) (31). Similar to the DEBQ, the EBPQ emotionaleating subscale captures eating driven by emotional states as opposed to internal hunger cues (e.g., "When I am in a bad mood, I eat whatever I feel like eating."). Cronbach's a coefficients for the two scales were 0.96 and 0.90 , respectively.

Food Cravings were assessed by the Food Craving Questionnaire - Trait (FCQ-T) (32). This 39-item questionnaire derives from the evidence that food cravings can be expressed both physiologically and psychologically. The nine factor-analytically derived scales measure cravings experienced as, or associated with positive reinforcement, negative reinforcement, cue-dependent eating, feelings of hunger, preoccupation with food, intentions to eat, lack of control, negative affect, and guilty feelings. Cronbach's a coefficient was 0.98 .

Snacking on Sweets was assessed with another subscale of the EBPQ, which reflects the extent to which the individual prefers foods with high-sugar content (e.g., "To me, cookies are an ideal snack food."). Other subscales of EBPQ were not included in our analysis, because they are not relevant to overeating. Cronbach's a coefficient was 0.77. 


\section{Laboratory Methods}

Blood samples for genetic analysis were collected on the day of clinical assessment. Blood lymphocyte DNA was extracted using the high-salt method (33). The four $M C 4 R$ single nucleotide polymorphisms (SNPs) genotyped as a part of this study (Table 1) were selected based on the literature on obesity and antipsychotic weight gain $(8,17,18)$ and these markers and their context sequence information for the $\mathrm{ABI}$ assays (available on demand) are as follows: GTTTAAAGCAGGAGAGATTGTATCC[C/ T]GATGGAAATGACAAGAAAAGCTTCA for rs17782313 (ABI assay ID: C_32667060_10), TCTTAATTCTGTTGTCATTAGTTCC[A/C]G TTTGTTAAATGTTTACAGCGTGGC for rs489693 (ABI assay ID: C__3058718_10), TAAGAACCCAGCCAGTAGTGGTTCA[A/G]TTAAAATACCTGAAAAACAGAGAGG for rs8087522 (ABI assay ID: C__29004626_10), and ATTATGAATGGGTTCAAAAGGGGTT [A/G]ATTTTAATGCACTAATATCCCATAT for rs11872992 (ABI assay ID: C__2747891_10). Due to having been associated with BMI in a number of important publications (10), we also included $M C 4 R$ rs571312 in our study. However, because it is well documented that rs571312 is in high linkage disequilibrium (LD) with rs17782313, we decided to analyze this SNP in a post hoc manner, separate from the other four SNPs. The context sequence information for the ABI assay (available on demand) for rs571312 is AAATTTGAGT TGCAGCTTTAAGTGA[A/ C]CTATGACCCGATGTTTGTGTAAAAT (ABI assay ID: C__ 797201_10). Polymerase chain reactions of $10 \mu \mathrm{l}$ volume using $20 \mathrm{ng}$ genomic DNA were performed using Assays-onDemand by Applied Biosystems Inc. (ABI; Carlsbad, CA) under the following conditions: $95^{\circ} \mathrm{C}$ for $10 \mathrm{~min}$, followed by 60 cycles of $92^{\circ} \mathrm{C} 15 \mathrm{~s}, 60^{\circ} \mathrm{C} 1 \mathrm{~min}$. Determination of alleles was performed using the ABI 7500 Sequence Detection System with the Allelic Discrimination software. Genotyping of the DNA was performed at the Neurogenetics Laboratory at the Centre for Addiction and Mental Health in Toronto, Canada, with laboratory staff blind to psychiatric diagnosis. For quality control purposes, $10 \%$ of the samples were re-genotyped, and ambiguous genotypes were excluded from the analysis.

\section{Statistical Methods}

Hardy-Weinberg equilibrium and LD were assessed using a chi-squared test through Haploview version 4.0. The relationships between MC4R genotypes and BMI measures were assessed using linear regression in SPSS 15.0 (genotype coded as 0 for TT, 1 for CT and 2 for CC), whereas UNPHASED version 3.1.5 was used to perform allelic analysis. For the quantitative analyses involving BMI, we corrected for multiple testing using Single Nucleotide Polymorphism Spectral Decomposition (SNPSpD; 34), determining the effective number of independent marker loci to be 3, thus setting the significance threshold $a$ at 0.017 .

Tests of mediation (also known as tests of indirect effects) are a common statistical approach in psychological science to test hypothesized processes (such as eating behaviours) linking distal variables (such as genetic vulnerability) and more proximal outcomes (such as weight). Originally based on the work of Baron and Kenny (35), tests of mediation assess whether putative mediating variables account for the association between a predictor variable and the outcome variable. More recent approaches assess whether the cross-product 
of path coefficient linking the predictor variable and the mediating variable (path a) and the path coefficient linking the mediating variable and the outcome variable (path $b$ ) is significantly different from zero. This approach uses bootstrapping to create $95 \%$ confidence intervals around the "true" value of this cross-product (referred to as the indirect effect). If zero is not within this confidence interval then the indirect (i.e., mediating) effect if significant. This approach can be extended to assess multiple mediators simultaneously. Multiple mediation analyses assess the significance of the indirect pathways via putative mediators as well as the overall mediation model. In order to test simultaneously whether the overeating behaviours and depressed mood accounted for the association between $M C 4 R$ (coded for the number of risk alleles present carried by an individual) and BMI, a multiple mediation model was tested according to the procedures described by Preacher and Hayes (36). As shown in Figure 1, path $c$ refers to the total effect of $M C 4 R$ on BMI in the absence of the mediators. Specific indirect effects refer to the influence of path $a \mathrm{x}$ path $b$ via each specific mediator ( $a_{1} \times b_{1}$ is the indirect effect of $M C 4 R$ on BMI via depressed mood; $a_{2} \mathrm{x}$ $b_{2}$ is the indirect effect of $M C 4 R$ on BMI via overeating behaviours). Multiple mediation analysis also allows statistical control over the correlations between the mediators. The total indirect effect reflects the summation of the specific indirect effects. Path $c^{\prime}$ refers to the direct effect of $M C 4 R$ on BMI when also controlling for the mediators.

Bias-corrected bootstrap confidence intervals ( $n=5000$, confidence intervals set at 95\%) were used to assess the significance of indirect effects. The SPSS "INDIRECT" macro developed to accompany the paper by Preacher and Hayes (36) was used to test the significance of the overall total indirect effect, as well as the significance of the specific individual mediators. The absence of zero in the confidence interval indicates significant indirect (i.e., mediated) effects.

\section{RESULTS}

\section{Sample Description}

Table 2 summarizes the genetic baseline characteristics of the participants included in the study. Minor allele frequencies for the MC4R loci in our sample were as follows: $23.3 \%$ for rs $571312,24.1 \%$ for $r s 17782313(n=322), 31.9 \%$ for rs489693 $(n=324), 30.3 \%$ for rs8087522 $(n=322)$, and $15.3 \%$ for rs $11872992(n=323)$. The average rate for successful genotyping across the SNPs was over 98\%, and all markers were in Hardy-Weinberg equilibrium. LD plot for the study sample is shown in Figure 2.

\section{The Association between MC4R Loci and BMI}

Table 3 summarizes the relationship between the MC4R common variants and BMI. In accord with previous studies (8-13), carriers of the rs17782313 minor allele had a higher BMI compared to carriers of the major allele. After correction for multiple testing, however, this finding was a strong trend that closely approached statistical significance $(p=0.018)$. Genotypic analysis revealed a dominant effect for the $\mathrm{C}$ allele, but this finding also fell short of statistical significance after correcting for multiple testing $(p=0.028)$. The other three $M C 4 R$ markers were not associated with BMI in our sample. 
MC4R rs571312 was analyzed separately from the other SNPs in a post hoc manner because it was in high LD with rs17782313. The association of rs571312 with BMI also did not reach significance following correction $(p=0.054$ for allelic analysis; $n=321$; results not shown).

\section{Associations among rs17782313, Overeating Behaviours, and Depressed Mood}

The rs $17782313 \mathrm{C}$ allele was significantly associated with elevated scores on the DEBQ Emotional Eating subscale $(r=0.17, p=0.004)$, the EBPQ Emotional Eating subscale $(r=0.15$, $p=0.01)$, and the FCQ-T $(r=0.20, p=0.013)$. None of the other $M C 4 R$ markers were related to scores on any of the other overeating measures. The $\mathrm{C}$ allele of the rs 17782313 polymorphism was also significantly associated with an increase in depressed mood, as assessed using the BDI ( $r=0.18, p=0.005)$. BDI and BMI were highly correlated $(r=0.33$, $p<0.001)$; similarly, BDI was significantly associated with the DEBQ Emotional Eating subscale $(r=0.54, p<0.001)$, the EBPQ Emotional Eating subscale $(r=0.50, p<0.001)$, and the FCQ-T ( $r=0.54, p<0.001)$. Due to the significant associations of rs17782313 with overeating behaviour and depressed mood, mediation analyses were carried out to test the indirect effect of the $M C 4 R$ marker on BMI, with depressed mood, and the overeating measures significantly associated with this marker (viz. the two emotional-eating variables and food cravings) as the mediators.

\section{Mediation Analyses}

Only 152 participants completed all measures used in the mediation analyses. The three overeating variables were highly correlated and appear to be measuring a shared construct. One strategy for managing highly correlated variables is to calculate a factor score to capture their shared variance. This approach resolves the problems associated with multicollinearity and increases scale reliability (37). Thus, an exploratory factor analysis was carried out to create a single composite score of the emotional-eating and craving variables. ${ }^{1}$ A single factor accounted for $86 \%$ of variance in the three overeating scales and all three loaded strongly on the factor (loadings ranging between 0.925 and 0.931 ).

As shown in Figure 1, the total indirect effect was statistically significant (unstandardized coefficient $=1.61 ; 95 \% \mathrm{CI}: 0.52-3.03$ ). However, only the overeating factor produced a significant specific indirect effect (Unstandardized coefficient $=1.31 ; 95 \%$ CI: $0.38-2.69$ ) after controlling for depressed mood. While depressed mood was significantly associated with $M C 4 R$ and BMI, the specific indirect effect was not significant (unstandardized coefficient $=0.31 ; 95 \% \mathrm{CI}:-0.21-1.25$ ). Therefore, whilst $M C 4 R$ rs 17782313 is associated with both depressed mood and emotional eating/cravings, only the latter shows a unique indirect effect to BMI (when controlling for depressed mood). ${ }^{2}$

\footnotetext{
${ }^{1}$ Data for this study were collected over a period of six years, and the FCQ was added as a measure about halfway through the data collection. Our exploratory analyses showed that the group with the FCQ scores was on average had a higher BMI than the group without the FCQ scores. The reason for this difference was that as the study progressed, the recruitment focus shifted to including individuals who were overweight, as this group gave us a greater spread of scores on our measures of overeating. To account for the missing data on the Food Cravings and emotional eating scales used in our study, data were imputed using Expectation Maximization Imputation and the model tested again $(n=322)$. Equivalent results were found with the imputed data with the total indirect effect $(1.43 ; 95 \%$ CI: $0.57-2.29)$ and the specific indirect effect via eating $(1.14 ; 95 \%$ CI: $0.44-1.93)$ significantly different from zero. The specific indirect effect via depressed mood remained non-significant (.28; 95\% CI: $-0.03-0.85)$.
} 


\section{DISCUSSION}

To date, little is known about the mechanisms by which $M C 4 R$ common variants contribute to high BMI, and only a few studies have investigated the role of eating behaviour in this association. Furthermore, despite the interconnections among the melanocortinergic, dopaminergic and serotonergic systems, $M C 4 R$-linked obesity has not been studied in relation to depressed mood. This project is the first to propose a possible mechanism to explain the relationship between $M C 4 R$ rs 17782313 and BMI. Specifically, we hypothesized two pathways by which MC4R may increase body weight: 1) via depressed mood and 2) via overeating behaviours. As discussed in the Results section, the rs17782313 polymorphism was associated with both depressed mood and emotional eating/cravings. However, when accounting for the shared variance between emotional eating and depressed mood, our analysis revealed that eating behavior alone (more specifically emotional eating and food cravings) accounted for the association between rs17782313 and BMI in our sample.

To our knowledge, the indirect effect of $M C 4 R$ rs 17782313 on BMI via emotional eating and food cravings is a novel pathway that has neither been proposed nor demonstrated before. The result of our mediation analysis is especially intriguing in that a causal link between depression/anhedonia and overeating has been well documented. One of the diagnostic criteria for major depressive disorder is a change in eating behaviour, and individuals suffering from atypical depression or seasonal affective disorder often present with overeating (38). Furthermore, patients with atypical depression-especially womenare more likely to be obese and present with higher BMI, waist-to-hip ratio, and percent fat mass compared to those with melancholic depression $(39,40)$. Although MC4R rs17782313 was associated with depressed mood in our study, current evidence does not suggest a specific indirect role for depressed mood in increased BMI in individuals carrying the risk allele. Considering the well-documented link between overeating and disinhibition (41-45) and in line with the recent findings published by Horstmann and colleagues (46) regarding the genotype-related gray matter volume differences in the prefrontal cortex, our results suggest a possible role for disinhibition and impulsivity rather than anhedonia with regards to $M C 4 R$-linked weight gain.

It is also important to mention that in accord with previous findings (8-13), we detected a positive trend between rs 17782313 and BMI. None of the markers associated with antipsychotic-induced weight gain (rs8087522 and rs489693) were related to BMI in our sample, suggesting that a different genetic mechanism may be responsible for medicationinduced changes in appetite. As we discussed, it was proposed that $M C 4 R$ variants may affect body mass via more proximal factors such as overeating. In particular, our preliminary results suggest a potential pathway to high BMI via emotionally-driven eating and the presence of the MC4R rs17782313 risk allele. Although our significant pathway did not involve depressed mood, our results suggest that the $\mathrm{C}$ allele of the rs17782313 polymorphism may play a role in the susceptibility to depression. We are unaware of any studies linking depression to $M C 4 R$ variants in humans; however, recent animal studies have

${ }^{2}$ The same models were also tested using the individual eating scales as the mediator of $M C 4 R$ and BMI and showed equivalent results as the factor score. 
shown that disruption of MC4R negates the effects of antidepressant medications (25) and that MC4R may be associated with anhedonia (26). The functionality of the near-MC4R region (which includes rs17782313) is currently not well understood, and preclinical studies are needed to investigate the biological mechanism underlying the links between $M C 4 R$ common variants and depressed mood.

In summary, while the rs 17782313 was the only polymorphism associated with BMI, it was also the only SNP related to overeating behaviours. Specifically, rs17782313 C allele was associated with increased emotional eating and food cravings. This particular polymorphism has been previously associated with increased food enjoyment and snacking on sweets (22, 23). In our study, however, the Snacking-on-Sweets measure was not linked to $M C 4 R$ variants, which meshes with a recent report showing that $M c 4 r$ knockout mice increase their overall level of food consumption without an increased preference for high-fat or high-sugar foods (47). A recently published imaging study has also provided preliminary evidence for $M C 4 R$ 's involvement with emotional eating (46), also in line with the findings of the present study.

Despite our novel findings, it is important to acknowledge some limitations of the current study. First, information on eating behaviours was obtained entirely from self-report measures. Therefore, since we did not include more objective measures from laboratory or observational paradigms, we must acknowledge the possibility of response bias. We also did not have complete data on the eating measures for all individuals included in the genetic analyses. In addition, the majority of our sample was women, and there have been numerous studies reporting sex differences for the effect of rs17782313 on various measures of food intake and body composition $(20,46,48)$. However, when controlling for sex in the mediation analyses, there was minimal change to our results, suggesting that the association we identified may not be sex-biased. Finally, we anticipate that these preliminary findings will assist other researchers with hypothesis generation for future studies with larger samples.

If replicated, our preliminary results have a number of possible clinical implications. First, $M C 4 R$ 's association with emotional eating and food cravings in our sample may suggest an MC4R-dopamine system interaction, especially considering that dopamine is highly expressed in the brain's reward pathways and the involvement of dopaminergic genes in overeating has been widely reported (49-52). Our group has also demonstrated a link between markers of the dopamine receptor D2 (DRD2) gene and emotional eating in binge eating disorder (53). Administration of agouti related protein, a melanocortin inverse agonist, is known to activate the dopaminergic neurons in the midbrain, to increase dopamine turnover in the prefrontal cortex, and to attenuate sucrose-seeking behaviour in rats (54), highlighting the possible link between MC4R, dopamine, and eating behaviour. Furthermore, MC4R signaling of dopamine 1 receptor neurons has been shown to play a role in procedural memory learning (55), as well as in stress-induced synaptic adaptations in the nucleus accumbens (26), thus suggesting an interaction between the dopamine (specifically DRD1) and the melanocortin systems in mood regulation. 
The serotonin system also plays a pivotal role in the regulation of eating and mood, and the interaction between MC4R and serotonergic system on energy balance has been well documented $(56,57)$. As a result of this, a possible genetic interaction between the serotonin system genes and MC4R may also be responsible for our findings in eating behaviour, highlighting the possibility of utilizing serotonin agonists in the treatment of MC4R-linked obesity. For instance, MC4R agonists (such as BIM-22493, BIM-22511) (58) may be helpful in the treatment of a subgroup of obese individuals with increased emotional eating and food cravings.

In conclusion, our results suggest that increased emotional eating and food cravings may account for the association between MC4R rs17782313 and BMI. Furthermore, although rs17782313 was also linked to depressed mood in our sample, the effect of this polymorphism on BMI was not via depression. If replicated, this proposed mechanism has the potential to have significant impact on our understanding of MC4R-linked weight gain and obesity.

\section{Acknowledgments}

This study was funded by a Canadian Institutes of Health Research (CIHR) operating grant awarded to Drs. Davis (PI), Carter, Kaplan, Kennedy, and Levitan. Dr. Yilmaz was funded by a CIHR Doctoral Research Award when the study was performed and is currently supported by the National Institutes of Health (NIH) Grant T32MH076694 (PI: Cynthia M. Bulik).

The authors would like to thank Dr. Jo Knight for statistical support and Ms. Natalie Freeman for laboratory support.

\section{References}

1. WHO Global Infobase. BMI/overweight/obesity Prevalence. World Health Organization; United States of America: 2006. Available from http://infobase.who.int

2. Fuemmeler BF, Agurs-Collins TD, McClernon FJ, Kollins SH, Kail ME, Bergen AW, et al. Genes implicated in serotonergic and dopaminergic functioning predict BMI categories. Obesity (Silver Spring). 2008; 16:348-355. [PubMed: 18239643]

3. Need AC, Ahmadi KR, Spector TD, Goldstein DB. Obesity is associated with genetic variants that alter dopamine availability. Ann Hum Genet. 2006; 70(Pt 3):293-303. [PubMed: 16674552]

4. Grayson BE, Seeley RJ. Deconstructing obesity: the face of fatness before and after the discovery of leptin. Diabetologia. 2012; 55:3-6. [PubMed: 22002009]

5. Huszar D, Lynch CA, Fairchild-Huntress V, Dunmore JH, Fang Q, Berkemeier LR, et al. Targeted disruption of the melanocortin-4 receptor results in obesity in mice. Cell. 1997; 88:131-141. [PubMed: 9019399]

6. Santini F, Maffei M, Pelosini C, Salvetti G, Scartabelli G, Pinchera A. Melanocortin-4 receptor mutations in obesity. Adv Clin Chem. 2009; 48:95-109. [PubMed: 19803416]

7. Srisai D, Gillum MP, Panaro BL, Zhang XM, Kotchabhakdi N, Shulman GI, et al. Characterization of the hyperphagic response to dietary fat in the MC4R knockout mouse. Endocrinology. 2011; 152:890-902. [PubMed: 21239438]

8. Loos RJ, Lindgren CM, Li S, Wheeler E, Zhao JH, Prokopenko I, et al. Common variants near MC4R are associated with fat mass, weight and risk of obesity. Nat Genet. 2008; 40:768-775. [PubMed: 18454148]

9. Willer CJ, Speliotes EK, Loos RJ, Li S, Lindgren CM, Heid IM, et al. Six new loci associated with body mass index highlight a neuronal influence on body weight regulation. Nat Genet. 2009; 41:2534. [PubMed: 19079261] 
10. Speliotes EK, Willer CJ, Berndt SI, Monda KL, Thorleifsson G, Jackson AU, et al. Association analyses of 249,796 individuals reveal 18 new loci associated with body mass index. Nat Genet. 2010; 42:937-948. [PubMed: 20935630]

11. Scherag A, Dina C, Hinney A, Vatin V, Scherag S, Vogel CI, et al. Two new Loci for body-weight regulation identified in a joint analysis of genome-wide association studies for early-onset extreme obesity in French and german study groups. PLoS Genet. 2010; 6:e1000916. [PubMed: 20421936]

12. Wang K, Li WD, Zhang CK, Wang Z, Glessner JT, Grant SF, et al. A genome-wide association study on obesity and obesity-related traits. PLoS One. 2011; 6:e18939. [PubMed: 21552555]

13. Paternoster L, Evans DM, Nohr EA, Holst C, Gaborieau V, Brennan P, et al. Genome-wide population-based association study of extremely overweight young adults - the GOYA study. PLoS One. 2011; 6:e24303. [PubMed: 21935397]

14. Beckers S, Zegers D, de Freitas F, Mertens IL, Van Gaal LF, Van Hul W. Association study of MC4R with complex obesity and replication of the rs17782313 association signal. Mol Genet Metab. 2011; 103:71-75. [PubMed: 21303735]

15. Kilpelainen TO, den Hoed M, Ong KK, Grontved A, et al. Brage SEarly Growth Genetics Consortium. Obesity-susceptibility loci have a limited influence on birth weight: a meta-analysis of up to 28,219 individuals. Am J Clin Nutr. 2011; 93:851-860. [PubMed: 21248185]

16. Zhao J, Bradfield JP, Zhang H, Sleiman PM, Kim CE, Glessner JT, et al. Role of BMI-associated loci identified in GWAS meta-analyses in the context of common childhood obesity in European Americans. Obesity (Silver Spring). 2011; 19:2436-2439. [PubMed: 21779088]

17. Malhotra AK, Correll CU, Chowdhury NI, Muller DJ, Gregersen PK, Lee AT, et al. Association between common variants near the melanocortin 4 receptor gene and severe antipsychotic druginduced weight gain. Arch Gen Psychiatry. 2012; 69:904-912. [PubMed: 22566560]

18. Chowdhury NI, Tiwari AK, Souza RP, Zai CC, Shaikh SA, Chen S, et al. Genetic association study between antipsychotic-induced weight gain and the melanocortin-4 receptor gene. Pharmacogenomics J. 2012; 13:272-279. [PubMed: 22310352]

19. Atalayer D, Robertson KL, Haskell-Luevano C, Andreasen A, Rowland NE. Food demand and meal size in mice with single or combined disruption of melanocortin type 3 and 4 receptors. Am J Physiol Regul Integr Comp Physiol. 2010; 298:R1667-R1674. [PubMed: 20375267]

20. Hasselbalch AL, Angquist L, Christiansen L, Heitmann BL, Kyvik KO, Sorensen TI. A variant in the fat mass and obesity-associated gene (FTO) and variants near the melanocortin-4 receptor gene (MC4R) do not influence dietary intake. J Nutr. 2010; 140:831-834. [PubMed: 20181787]

21. Bauer F, Elbers CC, Adan RA, Loos RJ, Onland-Moret NC, Grobbee DE, et al. Obesity genes identified in genome-wide association studies are associated with adiposity measures and potentially with nutrient-specific food preference. Am J Clin Nutr. 2009; 90:951-959. [PubMed: 19692490]

22. Valladares M, Dominguez-Vasquez P, Obregon AM, Weisstaub G, Burrows R, Maiz A, et al. Melanocortin-4 receptor gene variants in Chilean families: association with childhood obesity and eating behavior. Nutr Neurosci. 2010; 13:71-78. [PubMed: 20406574]

23. Ho-Urriola J, Guzman-Guzman IP, Smalley SV, Gonzalez A, Weisstaub G, Dominguez-Vasquez $\mathrm{P}$, et al. Melanocortin-4 receptor polymorphism rs 17782313: Association with obesity and eating in the absence of hunger in Chilean children. Nutrition. 2014; 30:145-149. [PubMed: 24139164]

24. Zhou L, Williams T, Lachey JL, Kishi T, Cowley MA, Heisler LK. Serotonergic pathways converge upon central melanocortin systems to regulate energy balance. Peptides. 2005; 26:17281732. [PubMed: 15993514]

25. Xu Y, Jones JE, Lauzon DA, Anderson JG, Balthasar N, Heisler LK, et al. A serotonin and melanocortin circuit mediates D-fenfluramine anorexia. J Neurosci. 2010; 30:14630-14634. [PubMed: 21048120]

26. Lim BK, Huang KW, Grueter BA, Rothwell PE, Malenka RC. Anhedonia requires MC4Rmediated synaptic adaptations in nucleus accumbens. Nature. 2012; 487:183-189. [PubMed: 22785313]

27. Beck AT, Ward CH, Mendelson M, Mock J, Erbaugh J. An inventory for measuring depression. Arch Gen Psychiatry. 1961; 4:561-571. [PubMed: 13688369] 
28. Halmi KA, Falk JR, Schwartz E. Binge-eating and vomiting: a survey of a college population. Psychol Med. 1981; 11:697-706. [PubMed: 6948315]

29. Lowe MR, Butryn ML, Didie ER, Annunziato RA, Thomas JG, Crerand CE, et al. The Power of Food Scale. A new measure of the psychological influence of the food environment. Appetite. 2009; 53:114-118. [PubMed: 19500623]

30. van Strien T, Frijters JER, Bergers GPA, Defares PB. The Dutch Eating Behavior Questionnaire (DEBQ) for assessment of restrained, emotional, and external eat- ing behavior. Int J Eat Disorder. 1986; 5:295-315.

31. Schlundt DG, Hargreaves MK, Buchowski MS. The Eating Behavior Patterns Questionnaire predicts dietary fat intake in African American women. J Am Diet Assoc. 2003; 103:338-345. [PubMed: 12616256]

32. Cepeda-Benito A, Gleaves DH, Williams TL, Erath SA. The development and vali- dation of the state and trait food-cravings questionnaires. Behav Ther. 2000; 31:151-173.

33. Lahiri DK, Nurnberger JI Jr. A rapid non-enzymatic method for the preparation of HMW DNA from blood for RFLP studies. Nucleic Acids Res. 1991; 19:5444. [PubMed: 1681511]

34. Nyholt DR. A simple correction for multiple testing for single-nucleotide poly- morphisms in linkage disequilibrium with each other. Am J Hum Genet. 2004; 74:765-769. [PubMed: 14997420]

35. Baron RM, Kenny DA. The moderator-mediator variable distinction in social psychological research: conceptual, strategic, and statistical considerations. J Pers Soc Psychol. 1986; 51:11731182. [PubMed: 3806354]

36. Preacher KJ, Hayes AF. Asymptotic and resampling strategies for assessing and comparing indirect effects in multiple mediator models. Behav Res Methods. 2008; 40:879-891. [PubMed: 18697684]

37. Hair, JF.; Black, B.; Babin, B.; Anderson, RE. Multivariate Data Analysis. 7. Pearson Education Inc; New Jersey: 2009.

38. American Psychiatric Association. Diagnostic and Statistical Manual of Mental Disorders. 5. American Psychiatric Association; Washington DC, USA: 2013.

39. Levitan RD, Davis C, Kaplan AS, Arenovich T, Phillips DI, Ravindran AV. Obesity comorbidity in unipolar major depressive disorder: refining the core phenotype. J Clin Psychiatry. 2012; 73:1119-1124. [PubMed: 22687640]

40. Cizza G, Ronsaville DS, Kleitz H, Eskandari F, Mistry S, Torvik S, et al. Clinical subtypes of depression are associated with specific metabolic parameters and circadian endocrine profiles in women: the power study. PLoS One. 2012; 7:e28912. [PubMed: 22235252]

41. Ganley RM. Emotional eating and how it relates to dietary restraint, disinhibition, and perceived hunger. Int J Eat Disorder. 1988; 7:635-647.

42. Kaplan AS, Howlett AL, Yilmaz Z, Levitan RD. Attention deficit hyperactivity disorder and binge eating: shared phenomenology, genetics and response to treatment. Int J Child Health Adolesc Health. 2009; 2:165.

43. Davis C. Attention-deficit/hyperactivity disorder: associations with overeating and obesity. Curr Psychiatry Rep. 2010; 12:389-395. [PubMed: 20632134]

44. Vannucci A, Tanofsky-Kraff M, Crosby RD, Ranzenhofer LM, Shomaker LB, Field SE, et al. Latent profile analysis to determine the typology of disinhibited eating behaviors in children and adolescents. J Consult Clin Psychol. 2013; 81:494-507. [PubMed: 23276121]

45. Mailloux G, Bergeron S, Meilleur D, D’Antono B, Dube I. Examining the associa- tions between overeating, disinhibition, and hunger in a nonclinical sample of college women. Int J Behav Med. 2013; 21:375-384. [PubMed: 23532565]

46. Horstmann A, Kovacs P, Kabisch S, Boettcher Y, Schloegl H, Tonjes A, et al. Common genetic variation near MC4R has a sex-specific impact on human brain structure and eating behavior. PLoS One. 2013; 8:e74362. [PubMed: 24066140]

47. Panaro BL, Cone RD. Melanocortin-4 receptor mutations paradoxically reduce preference for palatable foods. Proc Natl Acad Sci USA. 2013; 110:7050-7055. [PubMed: 23569235] 
48. Stutzmann F, Cauchi S, Durand E, Calvacanti-Proenca C, Pigeyre M, Hartikainen AL, et al. Common genetic variation near MC4R is associated with eating behaviour patterns in European populations. Int J Obes (Lond). 2009; 33:373-378. [PubMed: 19153581]

49. Levitan RD, Masellis M, Basile VS, Lam RW, Kaplan AS, Davis C, et al. The dopamine- 4 receptor gene associated with binge eating and weight gain in women with seasonal affective disorder: an evolutionary perspective. Biol Psychiatry. 2004; 56:665-669. [PubMed: 15522250]

50. Avena NM, Bocarsly ME, Rada P, Kim A, Hoebel BG. After daily bingeing on a sucrose solution, food deprivation induces anxiety and accumbens dopamine/ acetylcholine imbalance. Physiol Behav. 2008; 94:309-315. [PubMed: 18325546]

51. Davis C, Levitan RD, Kaplan AS, Carter J, Reid C, Curtis C, et al. Reward sensitivity and the D2 dopamine receptor gene: a case-control study of binge eating disorder. Prog Neuropsychopharmacol Biol Psychiatry. 2008; 32:620-628. [PubMed: 18262320]

52. Hersrud SL, Stoltenberg SF. Epistatic interaction between COMT and DAT1 genes on eating behavior: a pilot study. Eat Behav. 2009; 10:131-133. [PubMed: 19447357]

53. Davis C, Levitan RD, Yilmaz Z, Kaplan AS, Carter JC, Kennedy JL. Binge eating disorder and the dopamine D2 receptor: genotypes and sub-phenotypes. Prog Neuropsychopharmacol Biol Psychiatry. 2012; 38:328-335. [PubMed: 22579533]

54. Davis JF, Choi DL, Shurdak JD, Krause EG, Fitzgerald MF, Lipton JW, et al. Central melanocortins modulate mesocorticolimbic activity and food seeking behavior in the rat. Physiol Behav. 2011; 102:491-495. [PubMed: 21172367]

55. Cui H, Mason BL, Lee C, Nishi A, Elmquist JK, Lutter M. Melanocortin 4 receptor signaling in dopamine 1 receptor neurons is required for procedural memory learning. Physiol Behav. 2012; 106:201-210. [PubMed: 22342812]

56. Rowland NE, Fakhar KJ, Robertson KL, Haskell-Luevano C. Effect of serotonergic anorectics on food intake and induction of Fos in brain of mice with disruption of melanocortin 3 and/or 4 receptors. Pharmacol Biochem Behav. 2010; 97:107-111. [PubMed: 20347864]

57. Marston OJ, Garfield AS, Heisler LK. Role of central serotonin and melanocortin systems in the control of energy balance. Eur J Pharmacol. 2011; 660:70-79. [PubMed: 21216242]

58. Kumar KG, Sutton GM, Dong JZ, Roubert P, Plas P, Halem HA, et al. Analysis of the therapeutic functions of novel melanocortin receptor agonists in MC3R- and MC4R-deficient C57BL/6J mice. Peptides. 2009; 30:1892-1900. [PubMed: 19646498] 

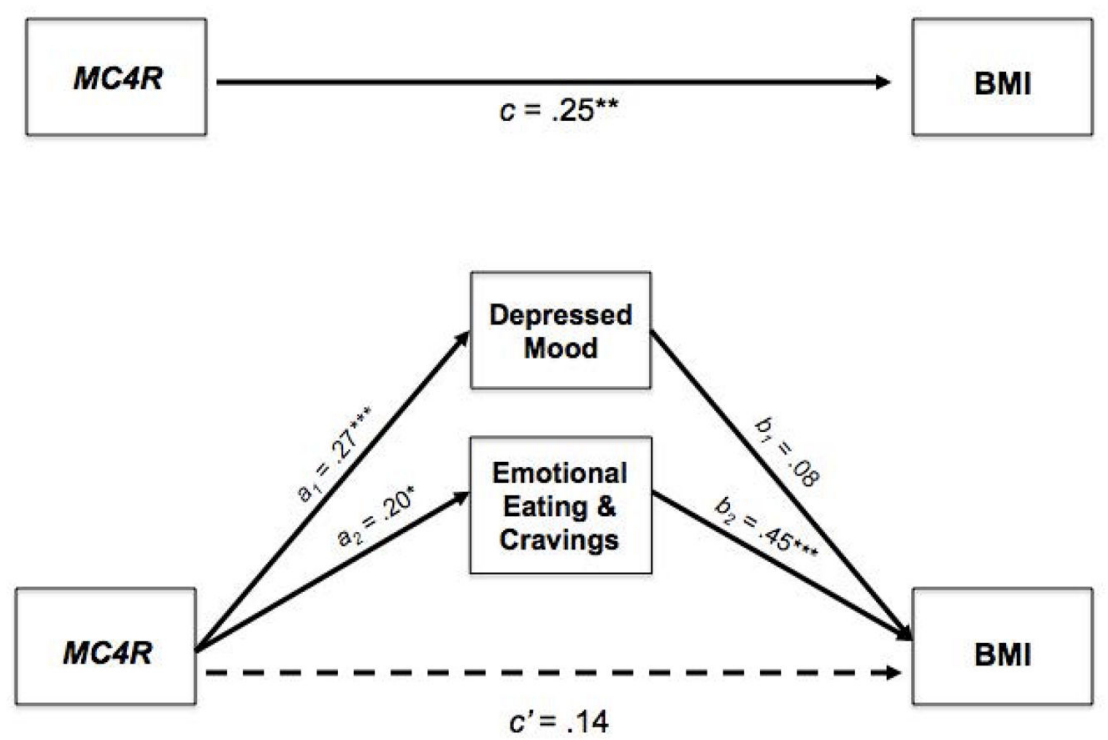

Total Indirect effect (Standardized) $=.11$, bias corrected $95 \% \mathrm{Cl}: .03-.20 ; R^{2}=0.30$ )

Figure 1.

Multiple mediation model of the relationship between MC4R, depressed mood, emotional eating/cravings, and BMI.

Note. Standardized coefficients are presented and tested for significance with $95 \%$ confidence intervals calculated using the bias-corrected bootstrap method (5000 samples). a = standardized IV to Med coefficient, $\mathrm{b}=$ standardized Med to DV coefficient, $\mathrm{c}=$ standardized total effect (IV to DV), $c^{\prime}=$ standardized direct effect. Subscripts refer to specific indirect paths.

$* \mathrm{p}<.05$

$* * \mathrm{p}<.01$

$* * * \mathrm{p}<.001$ 


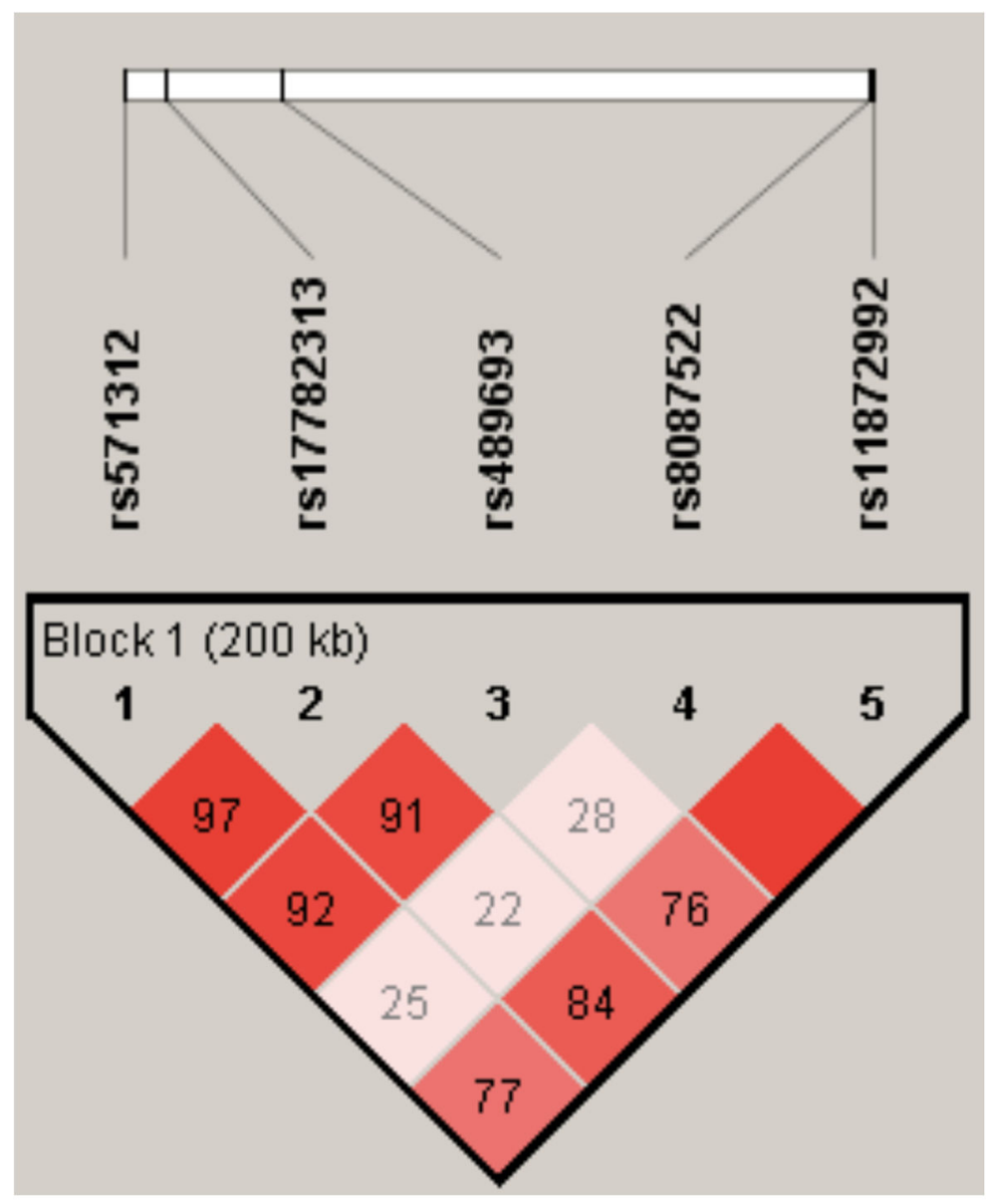

Figure 2.

Linkage disequilibrium plot for the five $M C 4 R$ markers. 
Table 1

$M C 4 R$ marker information

\begin{tabular}{lccc}
\hline MC4R marker & Region & Nucleotide substitution & Minor allele \\
\hline rs17782313 & Near $M C 4 R$ & $\mathrm{C} / \mathrm{T}$ & $\mathrm{C}$ \\
rs489693 & Near $M C 4 R$ & $\mathrm{~A} / \mathrm{C}$ & $\mathrm{A}$ \\
rs8087522 & $M C 4 R$ promoter & $\mathrm{A} / \mathrm{G}$ & $\mathrm{A}$ \\
rs11872992 & $M C 4 R$ promoter & $\mathrm{A} / \mathrm{G}$ & $\mathrm{A}$ \\
\hline
\end{tabular}




\section{Table 2}

Means and standard deviations (SD) for all quantitative variables in the study

\begin{tabular}{lccc}
\hline & Mean & SD & N \\
\hline Age (years) & 33.9 & 7.0 & 328 \\
BMI $\left(\mathrm{kg} / \mathrm{m}^{2}\right)$ & 31.8 & 9.5 & 327 \\
BDI & 10.6 & 9.6 & 250 \\
BEQ & 2.1 & 1.9 & 281 \\
PFS & 58.2 & 21.4 & 284 \\
DEBQ_Emot & 3.0 & 1.1 & 283 \\
EBPQ_Emot & 36.0 & 8.4 & 284 \\
EBPQ_Sweet & 17.5 & 4.9 & 284 \\
FCQ-T & 123.3 & 40.7 & 155 \\
\hline
\end{tabular}

Note. BMI=Body Mass Index; BDI=Beck Depression Inventory; BEQ=Binge Eating Questionnaire; PFS = Power of Food Scale;

DEBQ_Emot=Dutch Eating Behavior Questionnaire Emotional Eating subscale; EBPQ_Emot=Eating Behavior Patterns Questionnaire Emotional Eating subscale; EBPQ_Sweet=Eating Behavior Patterns Questionnaire Snacking on Sweets subscale; FCQ-T= Food Craving Questionnaire Trait. 
